\title{
A Best Proximity Point Theorem for Generalized Non-Self-Kannan-Type and Chatterjea-Type Mappings and Lipschitzian Mappings in Complete Metric Spaces
}

\author{
Kasamsuk Ungchittrakool ${ }^{1,2}$ \\ ${ }^{1}$ Department of Mathematics, Faculty of Science, Naresuan University, Phitsanulok 65000, Thailand \\ ${ }^{2}$ Research Center for Academic Excellence in Nonlinear Analysis and Optimization, Faculty of Science, \\ Naresuan University, Phitsanulok 65000, Thailand
}

Correspondence should be addressed to Kasamsuk Ungchittrakool; kasamsuku@nu.ac.th

Received 1 February 2016; Revised 5 May 2016; Accepted 7 June 2016

Academic Editor: Tomonari Suzuki

Copyright (C) 2016 Kasamsuk Ungchittrakool. This is an open access article distributed under the Creative Commons Attribution License, which permits unrestricted use, distribution, and reproduction in any medium, provided the original work is properly cited.

The purpose of this paper is to provide and study a best proximity point theorem for generalized non-self-Kannan-type and Chatterjea-type mappings and Lipschitzian mappings in complete metric spaces. The significant mapping in a unified form which related to contractive mappings, Kannan-type mappings, and Chatterjea-type mappings is established. We also provide some examples to illustrate the situation corresponding to the main theorem. The main result of this paper can be viewed as a general and unified form of several previously existing results.

\section{Introduction}

Fixed point theory can be looked upon as an important model that can be used in several real world problems and it is in close relationship with other branches of mathematics. It furnishes unified treatment and is a vital tool for solving equations of form $T x=x$, where $T$ is a self-mapping defined on a subset of some suitable spaces such as a metric space, a normed linear space, or a topological vector space. However, in case the mapping $T$ is not a self-mapping, the fixed point theorems are not specified to provide the existence of a solution for the equation $T x=x$. On the other hand, the best approximation theorems and the best proximity point theorems play an important rule to solve an approximate solution to the equation $T x=x$ when $T$ is a non-selfmapping, in which case a solution does not necessarily exist. For some interesting best approximation theorems, let us refer to [1-6]. For a non-self-mapping $T: A \rightarrow B$, a best proximity point theorem investigates the situations which lead to the existence of an element $x$ nearest to $T x$. It can be said on the other hand that a best proximity point theorem explores an element $x$ for which the value $d(x, T x)$ is minimum in the setting of metric spaces. This means that it is to study the global minimization of the real valued function $x \mapsto$ $d(x, T x)$. A best proximity point theorem succeeds in finding the global minimum of $x \mapsto d(x, T x)$ by constraining an approximate solution $x$ of the equation $T x=x$ to satisfy the condition that $d(x, T x)=d(A, B)$. The solutions of the equation $d(x, T x)=d(A, B)$ are called best proximity points of the mapping $T$. Furthermore, if $T$ is a self-mapping, then all best proximity points turn into the fixed points of $T$. With all these reasons, the study on best proximity point theorems is interesting and will cover the fixed point theorems implicitly.

For the previous research involving best proximity point theorems for several types of some mappings and contractions, one can refer to [7-17]. Best proximity point theorems for set valued mappings have been found in [18-28]. Moreover, in case of common best proximity point theorems, there are some interesting results in [29-32]. 
In 2013, Sadiq Basha et al. [33] established some best proximity point theorems for non-self-nonexpansive mappings, non-self-Kannan-type mappings, and non-self-Chatterjeatype mappings. Their results are quite interesting and there are examples to illustrate the main results.

Motivated and inspired by the research mentioned above, we are interested in studying a best proximity point theorem for generalized non-self-Kannan-type and Chatterjea-type mappings and Lipschitzian mappings in complete metric spaces with the way of an optimal approximate solution for $T x=x$ and $S y=y$, where $T: A \rightarrow B$ is a generalized non-self-Kannan-type and Chatterjea-type mapping and $S$ : $B \rightarrow A$ is a Lipschitzian mapping, respectively. The results obtained in this paper can be viewed as some extensions of the corresponding ones announced by Sadiq Basha et al. [33], Kannan [34], Chatterjea [35], and many others.

\section{Non-Self-Lipschitzian Mappings and Generalized Non-Self-Kannan-Type and Chatterjea-Type Mappings}

In this section, some definitions related to Lipschitzian mappings and their special forms are given and will be used in the sequel. The new mappings called generalized non-self-Kannan and Chatterjea mappings are established which are wider than non-self-Kannan mappings and non-self-Chatterjea mappings. Some other notions are provided and will be used in the next section.

Definition 1. Let $A$ and $B$ be nonempty subsets of a metric space $(M, d)$. An element $x^{*}$ in $A$ is said to be a best proximity point of a mapping $T: A \rightarrow B$ if $d\left(x^{*}, T x^{*}\right)=d(A, B)$.

It is noticed that best proximity becomes a fixed point if the underlying mapping is a self-mapping. Moreover, in light of the fact that $d(x, T x) \geq d(A, B)$ for all $x$ in $A$, the function $x \mapsto d(x, T x)$ attains its global minimum at a best proximity point.

Definition 2. Let $(M, d)$ and $(N, \rho)$ be two metric spaces. A mapping $S: M \rightarrow N$ is said to be a non-self-Lipschitzian mapping if there exists a constant $L \geq 0$ such that

$$
\rho(S x, S y) \leq L d(x, y)
$$

for all $x, y \in M$.

The smallest number $L$ for which (1) holds is called the Lipschitz constant of $S$.

Definition 3. Let $(M, d)$ and $(N, \rho)$ be two metric spaces. A Lipschitzian mapping $S: M \rightarrow N$ with the Lipschitz constant $L=1$ is said to be a non-self-nonexpansive mapping.

Definition 4. Let $(M, d)$ and $(N, \rho)$ be two metric spaces. A Lipschitzian mapping $S: M \rightarrow N$ with the Lipschitz constant $L<1$ is said to be a non-self-contractive mapping.
Definition 5. Let $A$ and $B$ be nonempty subsets of a metric space $(M, d)$. A mapping $T: A \rightarrow B$ is said to be

(1) a non-self-Kannan mapping (see [34] for the selfmapping case) if there exists a constant $k \in[0,1 / 2)$ such that

$$
d(T x, T y) \leq k(d(x, T x)+d(y, T y))
$$

for all $x, y \in A$;

(2) a non-self-Chatterjea mapping (see [35] for the selfmapping case) if there exists a constant $k \in[0,1 / 2)$ such that

$$
d(T x, T y) \leq k(d(x, T y)+d(y, T x))
$$

for all $x, y \in A$.

Definition 6. Let $A$ and $B$ be nonempty subsets of a metric space $(M, d)$. A mapping $T: A \rightarrow B$ is said to be a generalized non-self-Kannan and Chatterjea mapping if there exist nonnegative constants $k_{1}, k_{2}, k_{3}$ such that $k_{1}+2 k_{2}+2 k_{3}<1$ and

$$
\begin{aligned}
d(T x, T y) \leq & k_{1} d(x, y)+k_{2}(d(x, T x)+d(y, T y)) \\
& +k_{3}(d(x, T y)+d(y, T x))
\end{aligned}
$$

for all $x, y \in A$.

It is obvious that (4) is in a generalized form of (2) and (3).

Definition 7. Let $A$ and $B$ be nonempty subsets of a metric space $(M, d)$ and let $S: B \rightarrow A$ be a mapping. A mapping $T: A \rightarrow B$ is said to be

(1) a non-self-Kannan mapping with respect to the mapping $S$ if there exists a constant $k \in[0,1 / 2)$ such that

$$
d(T x, T y) \leq k(d(x, S T x)+d(y, S T y))
$$

for all $x, y \in A$;

(2) a non-self-Chatterjea mapping with respect to the mapping $S$ if there exists a constant $k \in[0,1 / 2)$ such that

$$
d(T x, T y) \leq k(d(x, S T y)+d(y, S T x))
$$

for all $x, y \in A$.

Definition 8. Let $A$ and $B$ be nonempty subsets of a metric space $(M, d)$ and let $S: B \rightarrow A$ be a mapping. A mapping $T: A \rightarrow B$ is said to be a generalized non-self-Kannan and Chatterjea mapping with respect to the mapping $S$ if there exist nonnegative constants $k_{1}, k_{2}, k_{3}$ such that $k_{1}+2 k_{2}+2 k_{3}<1$ and

$$
\begin{aligned}
d(T x, T y) \leq & k_{1} d(x, y)+k_{2}(d(x, S T x)+d(y, S T y)) \\
& +k_{3}(d(x, S T y)+d(y, S T x))
\end{aligned}
$$

for all $x, y \in A$. 
It is clear that (7) is in a generalized form of (5) and (6).

Definition 9 (see [33]). Let $A$ and $B$ be nonempty subsets of a metric space $(M, d)$. Given mappings $T: A \rightarrow B$ and $S: B \rightarrow$ $A$, the pair $(S, T)$ is said to form a weak $K$-cyclic contraction if there exists a nonnegative real number $k<1 / 2$ such that

$$
\begin{gathered}
d(T x, S T x) \leq k[d(x, T x)+d(T x, S T x)] \\
+(1-2 k) d(A, B)
\end{gathered}
$$

for all $x \in A$ and $y \in B$.

Definition 10 (see [33]). Let $A$ and $B$ be nonempty subsets of a metric space. Given mappings $T: A \rightarrow B$ and $S: B \rightarrow A$, the pair $(S, T)$ is said to form a $K$-cyclic contraction if there exists a nonnegative real number $k<1 / 2$ such that

$$
\begin{aligned}
d(T x, S y) \leq & k[d(x, T x)+d(y, S y)] \\
+ & (1-2 k) d(A, B)
\end{aligned}
$$

for all $x \in A$ and $y \in B$.

It is easy to observe that every $K$-cyclic contraction is a weak $K$-cyclic contraction.

\section{Main Results}

In this section, we establish and prove a best proximity point theorem for generalized non-self-Kannan-type and Chatterjea-type mappings and Lipschitzian mappings in complete metric spaces. Before going into the main theorem, it is useful to know the following observation.

Remark 11. Let $k_{1}, k_{2}, k_{3}$, and $L$ be nonnegative real numbers with $L \geq 1$ and satisfy

$$
0 \leq \frac{L\left(k_{1}+k_{2}+k_{3}\right)}{1-L\left(k_{2}+k_{3}\right)}<1 .
$$

Then the following hold:

(i) $1-L\left(k_{2}+k_{3}\right)>0$.

(ii) $0 \leq k_{1}+2 k_{2}+2 k_{3}<1$.

(iii) $1-\left(k_{1}+2 k_{3}\right)>0$.

(iv) $k_{1} \in[0,1)$ and $k_{2}, k_{3} \in[0,1 / 2)$.

Proof. Notice that (i) is directly obtained from (10). For (ii), we observe that

$$
\begin{aligned}
(10) & \Longrightarrow L\left(k_{1}+k_{2}+k_{3}\right)<1-L\left(k_{2}+k_{3}\right) \\
& \Longrightarrow k_{1}+k_{2}+k_{3}<\frac{1}{L}-\left(k_{2}+k_{3}\right) \\
& \Longrightarrow k_{1}+2 k_{2}+2 k_{3}<\frac{1}{L} \leq 1 .
\end{aligned}
$$

(iii) and (iv) are not hard to verify from (ii).
Theorem 12. Let $A$ and $B$ be nonempty closed subsets of $a$ complete metric space. Let $T: A \rightarrow B$ and $S: B \rightarrow A$ satisfy the following conditions:

(a) $S$ is a Lipschitzian mapping with Lipschitz constant $L \geq$ 1.

(b) There exist nonnegative constants $k_{1}, k_{2}, k_{3}$ such that $0 \leq\left(L\left(k_{1}+k_{2}+k_{3}\right)\right) /\left(1-L\left(k_{2}+k_{3}\right)\right)<1$.

(c) $d(T u, T v) \leq k_{1} d(u, v)+k_{2}(d(u, S T u)+d(v, S T v))+$ $k_{3}(d(u, S T v)+d(v, S T u))$ for all $u, v \in A$.

(d) The pair $(S, T)$ forms a weak K-cyclic contraction.

Then, there exist elements $x \in A$ and $y \in B$ such that

$$
\begin{aligned}
& d(x, T x)=d(A, B) \\
& d(y, S y)=d(A, B) \\
& d(x, y)=d(A, B) .
\end{aligned}
$$

If $x_{0}$ is any fixed element in $A, x_{2 n+1}=T x_{2 n}$, and $x_{2 n}=S x_{2 n-1}$, then the sequences $\left\{x_{2 n}\right\}$ and $\left\{x_{2 n+1}\right\}$ converge to some best proximity points of $T$ and $S$, respectively. Further, if $x^{*}$ is another best proximity point of $T$, then

$$
d\left(x, x^{*}\right) \leq \frac{2\left(1+2\left(k_{2}+k_{3}\right)\right)}{1-\left(k_{1}+2 k_{3}\right)} d(A, B) .
$$

Proof. Let $x_{0}$ be any fixed element in $A$. Then, it can generate the sequences $\left\{x_{2 n}\right\}$ and $\left\{x_{2 n+1}\right\}$ by $x_{2 n}=S x_{2 n-1}$ for all $n \geq 1$ and $x_{2 n+1}=T x_{2 n}$ for all $n \geq 0$, respectively. It is observed that

$$
\begin{aligned}
& d\left(x_{2 n}, x_{2 n+2}\right)=d\left(S x_{2 n-1}, S x_{2 n+1}\right) \\
& \quad \leq L d\left(x_{2 n-1}, x_{2 n+1}\right)=L d\left(T x_{2 n-2}, T x_{2 n}\right) \\
& \quad \leq L\left(k_{1} d\left(x_{2 n-2}, x_{2 n}\right)\right. \\
& \quad+k_{2}\left(d\left(x_{2 n-2}, S T x_{2 n-2}\right)+d\left(x_{2 n}, S T x_{2 n}\right)\right) \\
& \left.+k_{3}\left(d\left(x_{2 n-2}, S T x_{2 n}\right)+d\left(x_{2 n}, S T x_{2 n-2}\right)\right)\right) \\
& \quad=L\left(k_{1} d\left(x_{2 n-2}, x_{2 n}\right)\right. \\
& +k_{2}\left(d\left(x_{2 n-2}, x_{2 n}\right)+d\left(x_{2 n}, x_{2 n+2}\right)\right) \\
& \left.+k_{3}\left(d\left(x_{2 n-2}, x_{2 n+2}\right)+d\left(x_{2 n}, x_{2 n}\right)\right)\right) \\
& \quad \leq L\left(k_{1} d\left(x_{2 n-2}, x_{2 n}\right)\right. \\
& +k_{2}\left(d\left(x_{2 n-2}, x_{2 n}\right)+d\left(x_{2 n}, x_{2 n+2}\right)\right) \\
& \left.+k_{3}\left(d\left(x_{2 n-2}, x_{2 n}\right)+d\left(x_{2 n}, x_{2 n+2}\right)\right)\right)=L\left(k_{1}+k_{2}\right. \\
& \left.+k_{3}\right) d\left(x_{2 n-2}, x_{2 n}\right)+L\left(k_{2}\right. \\
& \left.+k_{3}\right) d\left(x_{2 n}, x_{2 n+2}\right) .
\end{aligned}
$$

It follows from (14) and Remark 11(i) that

$$
d\left(x_{2 n}, x_{2 n+2}\right) \leq \frac{L\left(k_{1}+k_{2}+k_{3}\right)}{1-L\left(k_{2}+k_{3}\right)} d\left(x_{2 n-2}, x_{2 n}\right) .
$$


By mathematical induction, we obtain

$$
d\left(x_{2 n}, x_{2 n+2}\right) \leq\left(\frac{L\left(k_{1}+k_{2}+k_{3}\right)}{1-L\left(k_{2}+k_{3}\right)}\right)^{n} d\left(x_{0}, x_{2}\right) .
$$

By using (b), it is not hard to verify that $\left\{x_{2 n}\right\}$ is a Cauchy sequence in $A$ and hence converges to some element $x$ in $A$. Similarly, we observe that

$$
\begin{aligned}
& d\left(x_{2 n+1}, x_{2 n+3}\right)=d\left(T x_{2 n}, T x_{2 n+2}\right) \\
& \leq k_{1} d\left(x_{2 n}, x_{2 n+2}\right) \\
&+k_{2}\left(d\left(x_{2 n}, S T x_{2 n}\right)+d\left(x_{2 n+2}, S T x_{2 n+2}\right)\right) \\
&+k_{3}\left(d\left(x_{2 n}, S T x_{2 n+2}\right)+d\left(x_{2 n+2}, S T x_{2 n}\right)\right) \\
&= k_{1} d\left(S x_{2 n-1}, S x_{2 n+1}\right) \\
&+k_{2}\left(d\left(S x_{2 n-1}, S x_{2 n+1}\right)+d\left(S x_{2 n+1}, S x_{2 n+3}\right)\right) \\
&+k_{3}\left(d\left(S x_{2 n-1}, S x_{2 n+3}\right)+d\left(S x_{2 n+1}, S x_{2 n+1}\right)\right) \\
& \leq k_{1} L d\left(x_{2 n-1}, x_{2 n+1}\right) \\
&+k_{2} L\left(d\left(x_{2 n-1}, x_{2 n+1}\right)+d\left(x_{2 n+1}, x_{2 n+3}\right)\right) \\
&+k_{3} L d\left(x_{2 n-1}, x_{2 n+3}\right) \\
& \leq k_{1} L d\left(x_{2 n-1}, x_{2 n+1}\right) \\
&+k_{2} L\left(d\left(x_{2 n-1}, x_{2 n+1}\right)+d\left(x_{2 n+1}, x_{2 n+3}\right)\right) \\
&+k_{3} L\left(d\left(x_{2 n-1}, x_{2 n+1}\right)+d\left(x_{2 n+1}, x_{2 n+3}\right)\right) \\
&= L\left(k_{1}+k_{2}+k_{3}\right) d\left(x_{2 n-1}, x_{2 n+1}\right) \\
&+L\left(k_{2}+k_{3}\right) d\left(x_{2 n+1}, x_{2 n+3}\right) .
\end{aligned}
$$

It follows from (17) and Remark 11(i) that

$$
d\left(x_{2 n+1}, x_{2 n+3}\right) \leq \frac{L\left(k_{1}+k_{2}+k_{3}\right)}{1-L\left(k_{2}+k_{3}\right)} d\left(x_{2 n-1}, x_{2 n+1}\right) .
$$

Therefore, mathematical induction yields

$$
d\left(x_{2 n+1}, x_{2 n+3}\right) \leq\left(\frac{L\left(k_{1}+k_{2}+k_{3}\right)}{1-L\left(k_{2}+k_{3}\right)}\right)^{n} d\left(x_{1}, x_{3}\right) .
$$

It follows from (b) that $\left\{x_{2 n+1}\right\}$ is a Cauchy sequence in $B$ and hence converges to some element $y$ in $B$. Furthermore, it can be observed that

$$
\begin{aligned}
& d\left(x_{2 n+2}, S T x\right)=d\left(S T x_{2 n}, S T x\right) \leq L d\left(T x_{2 n}, T x\right) \\
& \quad=L d\left(x_{2 n+1}, T x\right) \leq L\left(k_{1} d\left(x_{2 n}, x\right)\right. \\
& \quad+k_{2}\left(d\left(x_{2 n}, S T x_{2 n}\right)+d(x, S T x)\right) \\
& \left.\quad+k_{3}\left(d\left(x_{2 n}, S T x\right)+d\left(x, S T x_{2 n}\right)\right)\right) \\
& \quad=L\left(k_{1} d\left(x_{2 n}, x\right)\right. \\
& \quad+k_{2}\left(d\left(x_{2 n}, x_{2 n+2}\right)+d(x, S T x)\right) \\
& \left.\quad+k_{3}\left(d\left(x_{2 n}, S T x\right)+d\left(x, x_{2 n+2}\right)\right)\right) .
\end{aligned}
$$

Letting $n \rightarrow \infty$ in (20), it yields

$$
d(x, S T x) \leq L d(y, T x) \leq L\left(k_{2}+k_{3}\right) d(x, S T x) .
$$

Notice that $0 \leq L\left(k_{2}+k_{3}\right)<1$; it is not hard to verify that $d(y, T x)=0$ and then $T x=y$.

On the other hand, we also found that

$$
\begin{aligned}
& d\left(x_{2 n+3}, T S y\right)=d\left(T S x_{2 n+1}, T S y\right) \\
& \leq k_{1} d\left(S x_{2 n+1}, S y\right) \\
&+k_{2}\left(d\left(S x_{2 n+1}, S T S x_{2 n+1}\right)+d(S y, S T S y)\right) \\
&+k_{3}\left(d\left(S x_{2 n+1}, S T S y\right)+d\left(S y, S T S x_{2 n+1}\right)\right) \\
& \leq k_{1} L d\left(x_{2 n+1}, y\right)+k_{2} d\left(S x_{2 n+1}, x_{2 n+4}\right) \\
&+k_{2} L d(y, T S y) \\
&+k_{3} L\left(d\left(x_{2 n+1}, T S y\right)+d\left(y, x_{2 n+3}\right)\right) \\
&= k_{1} L d\left(x_{2 n+1}, y\right)+k_{2} d\left(S x_{2 n+1}, S x_{2 n+3}\right) \\
&+k_{2} L d(y, T S y) \\
&+k_{3} L\left(d\left(x_{2 n+1}, T S y\right)+d\left(y, x_{2 n+3}\right)\right) \\
& \leq k_{1} L d\left(x_{2 n+1}, y\right) \\
&+k_{2} L\left(d\left(x_{2 n+1}, x_{2 n+3}\right)+d(y, T S y)\right) \\
&+k_{3} L\left(d\left(x_{2 n+1}, T S y\right)+d\left(y, x_{2 n+3}\right)\right) .
\end{aligned}
$$

Letting $n \rightarrow \infty$ in (22), it yields

$$
\begin{aligned}
d(y, T S y) & \leq k_{2} d(S y, x)+L\left(k_{2}+k_{3}\right) d(y, T S y) \\
& \leq L\left(k_{2}+k_{3}\right) d(y, T S y) .
\end{aligned}
$$

This implies that $d(S y, x)=0$ and hence $S y=x$. Since the pair $(S, T)$ forms a weak $K$-cyclic contraction, it follows that there exists $k \in[0,1 / 2)$ such that

$$
\begin{aligned}
d(x, y)= & d(T x, S T x) \\
\leq & k[d(x, T x)+d(T x, S T x)] \\
& +(1-2 k) d(A, B) \\
\leq & 2 k d(x, y)+(1-2 k) d(A, B) \Longleftrightarrow \\
(1-2 k) d(x, y) \leq & (1-2 k) d(A, B) \Longleftrightarrow \\
d(x, y)= & d(A, B) .
\end{aligned}
$$

Hence

$$
d(A, B)=d(x, y)\left\{\begin{array}{l}
=d(x, T x)=d(T x, \text { ST } x) \\
=d(y, S y) .
\end{array}\right.
$$

This shows that $x$ is a best proximity point of $T$ and $y$ is a best proximity point of $S$. Similarly, if we suppose that $x^{*}$ is another best proximity point of $T$, it can be proved that

$$
d(A, B)=d\left(x^{*}, T x^{*}\right)=d\left(T x^{*}, S T x^{*}\right) .
$$


Consequently, it can be observed that

$$
\begin{aligned}
d( & \left.x, x^{*}\right) \leq d(x, T x)+d\left(T x, T x^{*}\right)+d\left(x^{*}, T x^{*}\right) \\
& \leq 2 d(A, B)+k_{1} d\left(x, x^{*}\right)+k_{2}(d(x, S T x) \\
& \left.+d\left(x^{*}, S T x^{*}\right)\right)+k_{3}\left(d\left(x, S T x^{*}\right)+d\left(x^{*}, S T x\right)\right) \\
& \leq 2 d(A, B)+k_{1} d\left(x, x^{*}\right)+k_{2}(d(x, T x) \\
& \left.+d(T x, S T x)+d\left(x^{*}, T x^{*}\right)+d\left(T x^{*}, S T x^{*}\right)\right) \\
& +k_{3}\left(d\left(x, x^{*}\right)+d\left(x^{*}, T x^{*}\right)+d\left(T x^{*}, S T x^{*}\right)\right. \\
& \left.+d\left(x^{*}, x\right)+d(x, T x)+d(T x, S T x)\right) \leq 2 d(A, B) \\
& +\left(k_{1}+2 k_{3}\right) d\left(x, x^{*}\right)+\left(k_{2}+k_{3}\right) \\
& +\left[d(x, T x)+d(T x, S T x)+d\left(x^{*}, T x^{*}\right)\right. \\
& \left.+d\left(T x^{*}, S T x^{*}\right)\right]=2 d(A, B)+\left(k_{1}\right. \\
+ & \left.2 k_{3}\right) d\left(x, x^{*}\right)+4\left(k_{2}+k_{3}\right) d(A, B) \\
& =2\left(1+2\left(k_{2}+k_{3}\right)\right) d(A, B)+\left(k_{1}\right. \\
+ & \left.2 k_{3}\right) d\left(x, x^{*}\right) .
\end{aligned}
$$

It follows from (29) and Remark 11(iii) that

$$
d\left(x, x^{*}\right) \leq \frac{2\left(1+2\left(k_{2}+k_{3}\right)\right)}{1-\left(k_{1}+2 k_{3}\right)} d(A, B) .
$$

This completes the proof of the theorem.

To achieve a better understanding of the situation of the main theorem even more, let us consider the following example to illustrate.

Example 13. Let $C[0, \pi]=\{f:[0, \pi] \rightarrow \mathbb{R} \mid f$ is continuous\} with supremum norm. Define the following two sets:

$$
\begin{aligned}
& A=\left\{f_{\alpha}:=1-\alpha \sin (\cdot) \mid \alpha \in[0,1]\right\}, \\
& B=\left\{g_{\beta}:=\beta \sin (\cdot)-1 \mid \beta \in[0,1]\right\} .
\end{aligned}
$$

It is not hard to verify that $A, B \subseteq C[0, \pi]$ and $A \cap B=\varnothing$. Define the mappings $T: A \rightarrow B$ and $S: B \rightarrow A$ by

$$
\begin{aligned}
T\left(f_{\alpha}\right) & =-f_{0.3 \sqrt{\alpha}}=g_{0.3 \sqrt{\alpha}}=0.3 \sqrt{\alpha} \sin (\cdot)-1, \\
S\left(g_{\beta}\right) & =-g_{\left(0.25+0.55 \beta^{2}\right)}=f_{\left(0.25+0.55 \beta^{2}\right)} \\
& =1-\left(0.25+0.55 \beta^{2}\right) \sin (\cdot)
\end{aligned}
$$

for all $\alpha, \beta \in[0,1]$ as shown in Figure 1 .

Then,

(1) All the conditions are consistent with all of the assumptions in Theorem 12.

(2) The mapping $S$ is a non-self-Lipschitzian mapping with constant $L=1.1$ which is not a non-selfnonexpansive mapping.

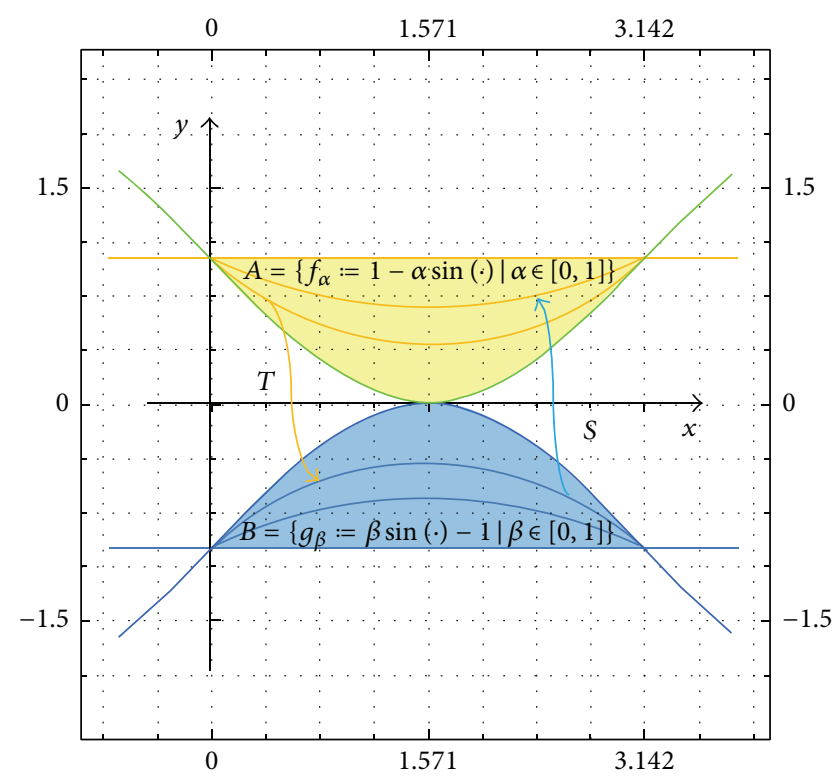

Figure $1: A$ and $B$ in the function space $\left(C[0, \pi],\|\cdot\|_{\infty}\right)$.

(3) There exist $f_{\alpha_{1}}, f_{\alpha_{2}} \in A$ such that $d\left(T\left(f_{\alpha_{1}}\right), T\left(f_{\alpha_{2}}\right)\right)>$ $0.5\left(d\left(f_{\alpha_{1}}, S T f_{\alpha_{1}}\right)+d\left(f_{\alpha_{2}}, S T f_{\alpha_{2}}\right)\right)$. That is, the mapping $T$ is not a non-self-Kannan-type mapping with respect to the mapping $S$.

(4) There exist $f_{\alpha_{1}}, f_{\alpha_{2}} \in A$ such that $d\left(T\left(f_{\alpha_{1}}\right), T\left(f_{\alpha_{2}}\right)\right)>$ $0.5 d\left(f_{\alpha_{1}}, S T f_{\alpha_{2}}\right)+d\left(f_{\alpha_{2}}, S T f_{\alpha_{1}}\right)$. That is, the mapping $T$ is not a non-self-Chatterjea-type mapping with respect to the mapping $S$.

Solution 1. (1) It is found that

$$
\begin{aligned}
d( & \left.T\left(f_{\alpha_{1}}\right), T\left(f_{\alpha_{2}}\right)\right)=\left\|T\left(f_{\alpha_{1}}\right)-T\left(f_{\alpha_{2}}\right)\right\| \\
& =\left\|0.3 \sqrt{\alpha_{1}} \sin (\cdot)-1-\left(0.3 \sqrt{\alpha_{2}} \sin (\cdot)-1\right)\right\| \\
& =0.3\left|\sqrt{\alpha_{1}}-\sqrt{\alpha_{2}}\right|\|\sin (\cdot)\|=0.3\left|\sqrt{\alpha_{1}}-\sqrt{\alpha_{2}}\right| .
\end{aligned}
$$

On the other hand, let us consider

$$
\begin{aligned}
d & \left(f_{\alpha_{1}}, S T f_{\alpha_{1}}\right)+d\left(f_{\alpha_{2}}, S T f_{\alpha_{2}}\right)=\left\|f_{\alpha_{1}}-S T f_{\alpha_{1}}\right\| \\
& +\left\|f_{\alpha_{2}}-S T f_{\alpha_{2}}\right\|=\| 1-\alpha_{1} \sin (\cdot) \\
& -S T\left(1-\alpha_{1} \sin (\cdot)\right)\|+\| 1-\alpha_{2} \sin (\cdot) \\
& -S T\left(1-\alpha_{2} \sin (\cdot)\right)\|=\| 1-\alpha_{1} \sin (\cdot) \\
& -S\left(0.3 \sqrt{\alpha_{1}} \sin (\cdot)-1\right)\|+\| 1-\alpha_{2} \sin (\cdot) \\
& -S\left(0.3 \sqrt{\alpha_{2}} \sin (\cdot)-1\right)\|=\| 1-\alpha_{1} \sin (\cdot) \\
& -\left(1-\left(0.25+0.55\left(0.09 \alpha_{1}\right)\right) \sin (\cdot)\right)\|+\| 1 \\
& -\alpha_{2} \sin (\cdot)-\left(1-\left(0.25+0.55\left(0.09 \alpha_{2}\right)\right) \sin (\cdot)\right) \| \\
& =\left|0.25+0.0495 \alpha_{1}-\alpha_{1}\right|\|\sin (\cdot)\|+\mid 0.25 \\
& +0.0495 \alpha_{2}-\alpha_{2}|\|\sin (\cdot)\|=| 0.25-0.9505 \alpha_{1} \mid \\
& +\left|0.25-0.9505 \alpha_{2}\right|,
\end{aligned}
$$




$$
\begin{aligned}
d( & \left.f_{\alpha_{1}}, S T f_{\alpha_{2}}\right)+d\left(f_{\alpha_{2}}, S T f_{\alpha_{1}}\right)=\left\|f_{\alpha_{1}}-S T f_{\alpha_{2}}\right\| \\
& +\left\|f_{\alpha_{2}}-S T f_{\alpha_{1}}\right\|=\| 1-\alpha_{1} \sin (\cdot) \\
& -S T\left(1-\alpha_{2} \sin (\cdot)\right)\|+\| 1-\alpha_{2} \sin (\cdot) \\
& -S T\left(1-\alpha_{1} \sin (\cdot)\right)\|=\| 1-\alpha_{1} \sin (\cdot) \\
& -S\left(0.3 \sqrt{\alpha_{2}} \sin (\cdot)-1\right)\|+\| 1-\alpha_{2} \sin (\cdot) \\
& -S\left(0.3 \sqrt{\alpha_{1}} \sin (\cdot)-1\right)\|=\| 1-\alpha_{1} \sin (\cdot) \\
& -\left(1-\left(0.25+0.55\left(0.09 \alpha_{2}\right)\right) \sin (\cdot)\right)\|+\| 1 \\
& -\alpha_{2} \sin (\cdot)-\left(1-\left(0.25+0.55\left(0.09 \alpha_{1}\right)\right) \sin (\cdot)\right) \| \\
& =\left|0.25+0.0495 \alpha_{2}-\alpha_{1}\right|\|\sin (\cdot)\|+\mid 0.25 \\
& +0.0495 \alpha_{1}-\alpha_{2}|\|\sin (\cdot)\|=| 0.25+0.0495 \alpha_{2}-\alpha_{1} \mid \\
& +\left|0.25+0.0495 \alpha_{1}-\alpha_{2}\right| \cdot
\end{aligned}
$$

For convenience for writing, we will let $x=\alpha_{1}$ and $y=\alpha_{2}$. From (29), (34), and (35), it is sufficient to show that

$$
\begin{aligned}
0.3|\sqrt{x}-\sqrt{y}| \leq & 0.45|x-y|+0.1|0.25-0.9505 x| \\
& +0.1|0.25-0.9505 y| \\
& +0.1|0.25+0.0495 y-x| \\
& +0.1|0.25+0.0495 x-y|
\end{aligned}
$$

for all $x, y \in[0,1]$. Now, we let

(1) $F(x, y)=0.3|\sqrt{x}-\sqrt{y}|$.

(2) $G(x, y)=0.45|x-y|+0.1|0.25-0.9505 x|+0.1 \mid 0.25-$ $0.9505 y|+0.1| 0.25+0.0495 y-x|+0.1| 0.25+0.0495 x-$ $y \mid$

for all $x, y \in[0,1]$. The two surfaces $F(x, y)$ and $G(x, y)$ can be illustrated as in Figure 2.

The idea to prove $(36)$ is to divide the unit square $[0,1] \times$ $[0,1]$ of $x y$-plane into six parts as shown in Figure 3.

(1) We will show that (36) is true on the area $A_{1}=$ $\left\{(x, y) \in[0,1]^{2} \mid y \leq x \leq 0.25+0.0495 y\right\}$. It is clear that $|\sqrt{x}-\sqrt{y}|=(\sqrt{x}-\sqrt{y}),|x-y|=(x-y)$, and $\mid 0.25+0.0495 y-$ $x \mid=(0.25+0.0495 y-x)$ for all $(x, y) \in A_{1}$. Since $(x, y) \in A_{1}$, then $y \leq x \leq 0.25+0.0495 y \leq 0.25+0.0495 x$. It implies that $0.9505 x \leq 0.25,0.9505 y \leq 0.25$, and $y \leq 0.25+0.0495 x$ and then $|0.25-0.9505 x|=(0.25-0.9505 x),|0.25-0.9505 y|=$ $(0.25-0.9505 y)$, and $|0.25+0.0495 x-y|=(0.25+0.0495 x-y)$. Thus, we have

$$
\begin{aligned}
& 0.45|x-y|+0.1|0.25-0.9505 x| \\
& \quad+0.1|0.25-0.9505 y|+0.1|0.25+0.0495 y-x| \\
& \quad+0.1|0.25+0.0495 x-y|=0.45(x-y) \\
& \quad+0.1(0.25-0.9505 x)+0.1(0.25-0.9505 y)
\end{aligned}
$$

$$
\begin{aligned}
& +0.1(0.25+0.0495 x-y) \\
& +0.1(0.25+0.0495 y-x)=0.45 x-0.45 y \\
& +0.025-0.09505 x+0.025-0.09505 y+0.025 \\
& +0.00495 x-0.1 y+0.025+0.00495 y-0.1 x \\
& =(0.45-0.09505+0.00495-0.1) x \\
& +(-0.45-0.09505-0.1+0.00495) y \\
& +(0.025+0.025+0.025+0.025)=0.2599 x \\
& -0.6401 y+0.1
\end{aligned}
$$

Thus it is sufficient to show that $0.3(\sqrt{x}-\sqrt{y}) \leq 0.2599 x-$ $0.6401 y+0.1$ or equivalently to show that

$$
0.3 \sqrt{x}-0.2599 x \leq 0.3 \sqrt{y}-0.6401 y+0.1 \text {. }
$$

Define

$$
\begin{aligned}
& \varphi(x)=0.3 \sqrt{x}-0.2599 x \\
& \psi(y)=0.3 \sqrt{y}-0.6401 y+0.1
\end{aligned}
$$

for all $x, y \in[0,500 / 1901(=0.25 / 0.9505 \approx 0.263)]$. It is not hard to compute that

$$
\varphi^{\prime}(x)=\frac{0.15}{\sqrt{x}}-0.2599>0
$$

for all $x \in(0,500 / 1901)$. Thus $\varphi$ is an increasing function on $[0,500 / 1901]$. This implies that

$$
\begin{aligned}
0.3 \sqrt{x}-0.2599 x & \leq \varphi\left(\frac{500}{1901}\right) \\
& =0.3 \sqrt{\frac{500}{1901}}-0.2599\left(\frac{500}{1901}\right) \\
& =0.3 \sqrt{\frac{500}{1901}}-\frac{2599}{38020} \approx 0.0854975
\end{aligned}
$$

for all $x \in[0,500 / 1901]$. On the other hand,

$$
\psi^{\prime}(y)=\frac{0.15}{\sqrt{y}}-0.6401
$$

for all $y \in(0,500 / 1901)$. It is found that $y=(0.15 / 0.6401)^{2} \approx$ $0.05491 \in(0,500 / 1901)$ is the critical point of $\psi$ providing the absolute maximum value

$$
\begin{aligned}
\psi\left(\left(\frac{0.15}{0.6401}\right)^{2}\right)= & 0.3\left(\frac{0.15}{0.6401}\right) \\
& -0.6401\left(\frac{0.15}{0.6401}\right)^{2}+0.1 \\
= & \frac{8651}{64010} \approx 0.13515
\end{aligned}
$$




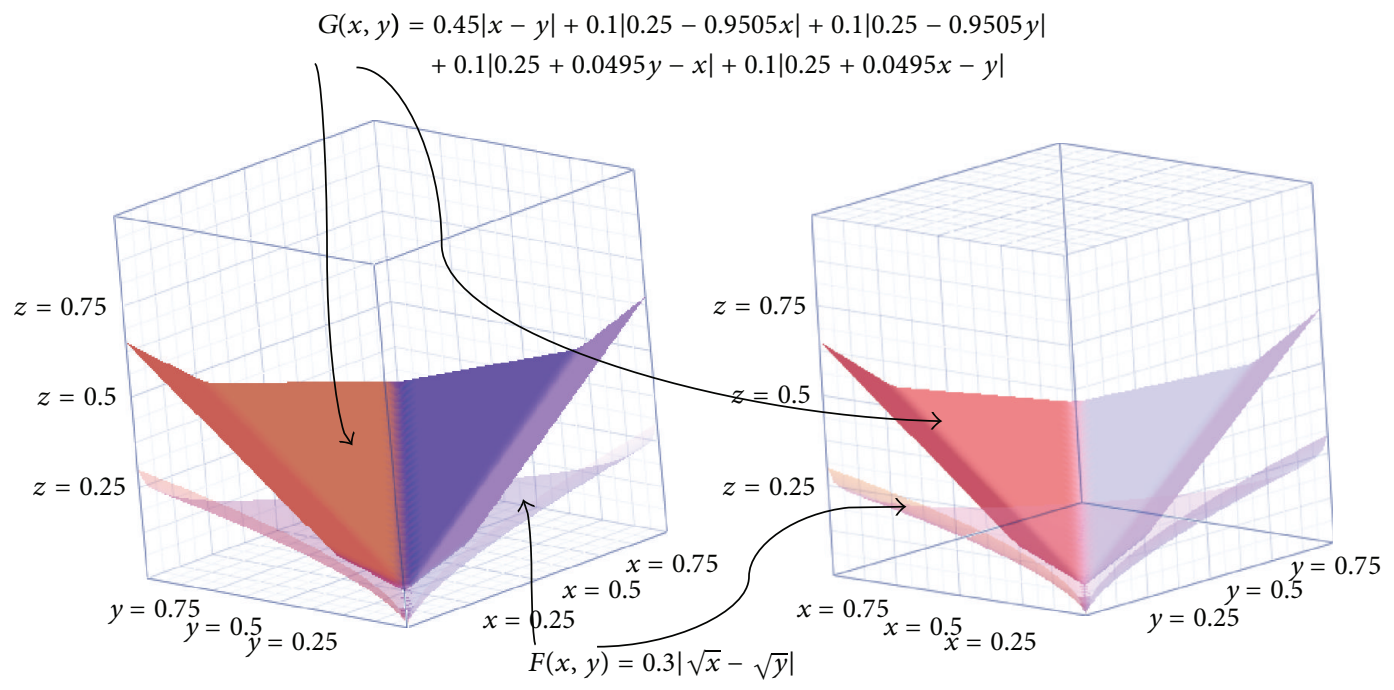

Figure 2: Two surfaces $F(x, y) \leq G(x, y)$ in the unit cube.

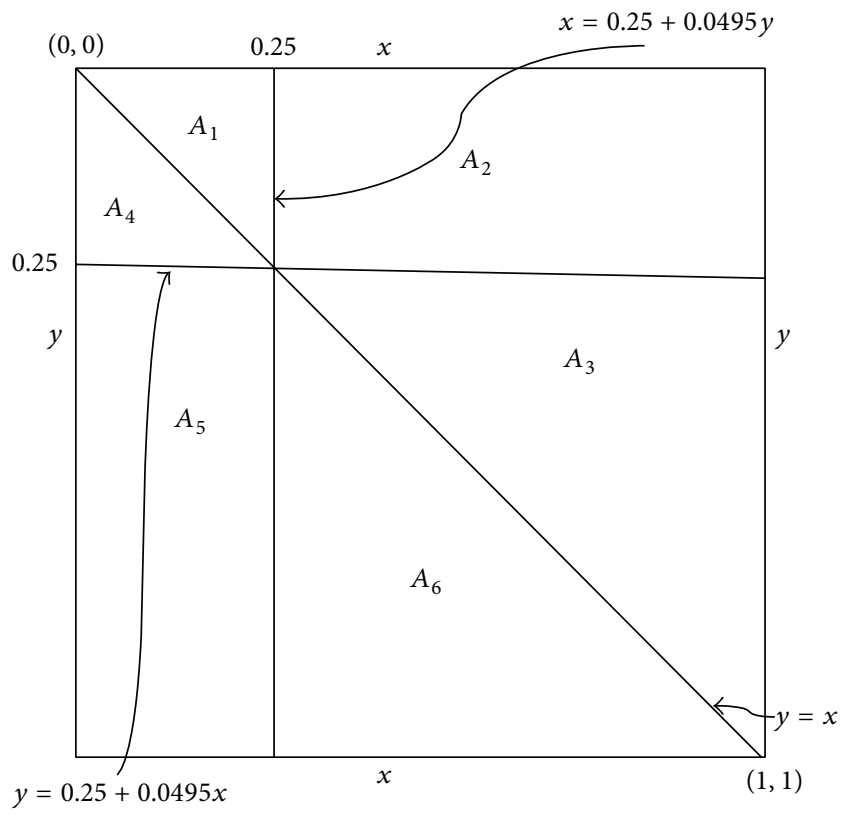

Figure 3: $A_{1}, A_{2}, A_{3}, A_{4}, A_{5}$, and $A_{6}$ on the unit square.

on $[0,500 / 1901]$. It is not hard to see that $\psi$ is an increasing function on $\left[0,(0.15 / 0.6401)^{2}\right]$ and $\psi$ is a decreasing function on $\left[(0.15 / 0.6401)^{2}, 500 / 1901\right]$. Notice that the starting point $y=0$ provides the value $\psi(0)=0.1(>\varphi(500 / 1901) \approx$ 0.0854975 ) and then it implies that the end point $y=$ $500 / 1901$ provides the absolute minimum value

$$
\begin{aligned}
\psi\left(\frac{500}{1901}\right) & =0.3 \sqrt{\frac{500}{1901}}-0.6401\left(\frac{500}{1901}\right)+0.1 \\
& =0.3 \sqrt{\frac{500}{1901}}-\frac{2599}{38020}=\varphi\left(\frac{500}{1901}\right) \\
& \approx 0.0854975
\end{aligned}
$$

on $[0,500 / 1901]$. Therefore, $\psi(500 / 1901) \leq 0.3 \sqrt{y}-$ $0.6401 y+0.1$ for all $y \in[0,500 / 1901]$. Thus, we have

$$
\begin{aligned}
0.3 \sqrt{x}-0.2599 x & \leq \varphi\left(\frac{500}{1901}\right)=\psi\left(\frac{500}{1901}\right) \\
& \leq 0.3 \sqrt{y}-0.6401 y+0.1
\end{aligned}
$$

for all $(x, y) \in A_{1}$.

(2) For the area $A_{2}=\left\{(x, y) \in[0,1]^{2} \mid x \geq 0.25+\right.$ $0.0495 y$ and $y \leq 0.25+0.0495 x\}$, one can study from the proof of the area $A_{1}$ to verify that (36) holds for all $(x, y) \in$ $A_{2}$.

(3) For the area $A_{3}=\left\{(x, y) \in[0,1]^{2} \mid 0.25+0.0495 x \leq\right.$ $y \leq x\}$, one can study from the proof of the area $A_{1}$ to conclude that (36) is true for all $(x, y) \in A_{3}$.

Notice that the graph of the two surfaces $F(x, y)$ and $G(x, y)$ has symmetry. Therefore, (36) is also true for the areas

$$
\begin{aligned}
A_{4} & =\left\{(x, y) \in[0,1]^{2} \mid x \leq y \leq 0.25+0.0495 x\right\}, \\
A_{5} & =\left\{(x, y) \in[0,1]^{2} \mid x \leq 0.25+0.0495 y \text { and } y\right. \\
& \geq 0.25+0.0495 x\}, \\
A_{6} & =\left\{(x, y) \in[0,1]^{2} \mid 0.25+0.0495 y \leq x \leq y\right\} .
\end{aligned}
$$

Hence we can conclude that (36) holds for all $x, y \in$ $[0,1]$. This shows that $T$ is a generalized non-self-Kannan and Chatterjea mapping with respect to the mapping $S$ with constants $k_{1}=0.45, k_{2}=k_{3}=0.1$.

Further, it can be verified that

$$
\frac{L\left(k_{1}+k_{2}+k_{3}\right)}{1-L\left(k_{2}+k_{3}\right)}=\frac{1.1(0.45+0.1+0.1)}{1-1.1(0.1+0.1)}=\frac{0.715}{0.78}
$$


We observe that the pair $(S, T)$ is a weak $K$-cyclic contraction. For this fact, let us consider

$$
\begin{aligned}
d & \left(T f_{\alpha}, S T f_{\alpha}\right)=\left\|T f_{\alpha}-S T f_{\alpha}\right\|=\| T(1-\alpha \sin (\cdot)) \\
& -S T(1-\alpha \sin (\cdot))\|=\| 0.3 \sqrt{\alpha} \sin (\cdot)-1 \\
& -S(0.3 \sqrt{\alpha} \sin (\cdot)-1)\|=\| 0.3 \sqrt{\alpha} \sin (\cdot)-1 \\
& -(1-(0.25+0.55(0.09 \alpha)) \sin (\cdot)) \| \\
& =\|(0.25+0.3 \sqrt{\alpha}+0.0495 \alpha) \sin (\cdot)-2\|=2
\end{aligned}
$$

and then

$$
\begin{aligned}
d & \left(f_{\alpha}, T f_{\alpha}\right)+d\left(T f_{\alpha}, S T f_{\alpha}\right) \\
& =\left\|f_{\alpha}-T f_{\alpha}\right\|+\left\|T f_{\alpha}-S T f_{\alpha}\right\| \\
& =\|1-\alpha \sin (\cdot)-T(1-\alpha \sin (\cdot))\|+2 \\
& =\|1-\alpha \sin (\cdot)-(0.3 \sqrt{\alpha} \sin (\cdot)-1)\|+2 \\
& =\|2-(\alpha+0.3 \sqrt{\alpha}) \sin (\cdot)\|+2=2+2=4 .
\end{aligned}
$$

Therefore, for any $k \in[0,1 / 2)$ it can be seen that

$$
\begin{aligned}
d\left(T f_{\alpha}, S T f_{\alpha}\right)= & 2 \leq 2=4 k+(1-2 k) 2 \\
= & k\left[d\left(f_{\alpha}, T f_{\alpha}\right)+d\left(T f_{\alpha}, S T f_{\alpha}\right)\right] \\
& +(1-2 k) d(A, B) .
\end{aligned}
$$

(2) It can be observed that the mapping $S$ is a non-selfLipschitzian mapping with constant $L=1.1$ but it is not a non-self-nonexpansive mapping as follows:

$$
\begin{gathered}
d\left(S\left(g_{\beta_{1}}\right), S\left(g_{\beta_{2}}\right)\right)=\|\left(1-\left(0.25+0.55 \beta_{1}^{2}\right) \sin (\cdot)\right) \\
\quad-\left(1-\left(0.25+0.55 \beta_{2}^{2}\right) \sin (\cdot)\right) \|=0.5\left|\beta_{1}^{2}-\beta_{2}^{2}\right| \\
\cdot\|\sin (\cdot)\|=0.55\left|\beta_{1}+\beta_{2}\right|\left|\beta_{1}-\beta_{2}\right| \leq 0.55(2) \mid \beta_{1} \\
-\beta_{2}|=1.1| \beta_{1}-\beta_{2} \mid=1.1 d\left(g_{\beta_{1}}, g_{\beta_{2}}\right) .
\end{gathered}
$$

Therefore, $S$ is a non-self-Lipschitzian mapping with constant $L=1.1$. We note that the mapping $S$ is not a non-selfnonexpansive mapping. Indeed, if we let $\beta_{1}=0.99$ and $\beta_{2}=$ 1 , then

$$
\begin{aligned}
d\left(S\left(g_{\beta_{1}}\right), S\left(g_{\beta_{2}}\right)\right) & =0.55(0.99+1)|0.99-1| \\
& =0.010945>0.01=\left|\beta_{1}-\beta_{2}\right| \\
& =d\left(g_{\beta_{1}}, g_{\beta_{2}}\right) .
\end{aligned}
$$

(3) The mapping $T$ is not a non-self-Kannan-type mapping with respect to the mapping $S$.

To guarantee this truth, we let $\alpha_{1}=0$ and $\alpha_{2}=0.25$, and it follows from (33) that

$$
\begin{aligned}
d\left(T\left(f_{0}\right), T\left(f_{0.25}\right)\right) & =0.3|\sqrt{0}-\sqrt{0.25}|=0.3(0.5) \\
& =0.15
\end{aligned}
$$

and by using (34), we have

$$
\begin{aligned}
0.5 & \left(d\left(f_{0}, S T f_{0}\right)+d\left(f_{0.25}, S T f_{0.25}\right)\right) \\
& =0.5(|0.25-0.9505(0)|+|0.25-0.9505(0.25)|) \\
& =0.1311875
\end{aligned}
$$

Comparing (53) and (54), we obtain

$$
\begin{aligned}
& d\left(T\left(f_{0}\right), T\left(f_{0.25}\right)\right) \\
& >0.5\left(d\left(f_{0}, S T f_{0}\right)+d\left(f_{0.25}, S T f_{0.25}\right)\right) \\
& >k\left(d\left(f_{0}, S T f_{0}\right)+d\left(f_{0.25}, S T f_{0.25}\right)\right)
\end{aligned}
$$

for all $k \in[0,1 / 2)$. Therefore, $T$ is not a non-self-Kannan-type mapping with respect to the mapping $S$.

(4) The mapping $T$ is not a non-self-Chatterjea-type mapping with respect to the mapping $S$.

In order to guarantee this fact, we let $\alpha_{1}=0$ and $\alpha_{2}=0.25$; it follows from (35) that

$$
\begin{aligned}
0.5 & \left(d\left(f_{0}, S T f_{0.25}\right)+d\left(f_{0.25}, S T f_{0}\right)\right) \\
& =0.5(|0.25+0.0495(0.25)-0| \\
& +|0.25+0.0495(0)-0.25|)=0.1311875 .
\end{aligned}
$$

Comparing (53) and (56), we obtain

$$
\begin{aligned}
d( & \left.\left(f_{0}\right), T\left(f_{0.25}\right)\right) \\
> & 0.5\left(d\left(f_{0}, S T f_{0.25}\right)+d\left(f_{0.25}, S T f_{0}\right)\right) \\
> & k\left(d\left(f_{0}, S T f_{0.25}\right)+d\left(f_{0.25}, S T f_{0}\right)\right)
\end{aligned}
$$

for all $k \in[0,1 / 2)$. Therefore, $T$ is not a non-self-Chatterjeatype mapping with respect to the mapping $S$.

If the mapping $S$ in Example 13 is a nonexpansive mapping, then the mapping $T$ in the following example still cannot be both a non-self-Kannan-type mapping with respect to the mapping $S$ and a non-self-Chatterjea-type mapping with respect to the mapping $S$. However, the mapping $T$ is still to maintain its general property; that is, $T$ is a generalized non-self-Kannan and Chatterjea mapping with respect to the mapping $S$.

Example 14. Let $C[0, \pi], A, B$, and $T$ be as in Example 13 . Define $S: B \rightarrow A$ by

$$
\begin{aligned}
S\left(g_{\beta}\right) & =-g_{\left(0.25+0.5 \beta^{2}\right)}=f_{\left(0.25+0.5 \beta^{2}\right)} \\
& =1-\left(0.25+0.5 \beta^{2}\right) \sin (\cdot)
\end{aligned}
$$

for all $\beta \in[0,1]$. Then,

(i) All the conditions are consistent with all of the assumptions in Theorem 12.

(ii) The mapping $S$ is a non-self-nonexpansive mapping. 
(ii) There exist $f_{\alpha_{1}}, f_{\alpha_{2}} \in A$ such that $d\left(T\left(f_{\alpha_{1}}\right), T\left(f_{\alpha_{2}}\right)\right)>$ $0.5\left(d\left(f_{\alpha_{1}}, S T f_{\alpha_{1}}\right)+d\left(f_{\alpha_{2}}, S T f_{\alpha_{2}}\right)\right)$. That is, the mapping $T$ is not a non-self-Kannan-type mapping with respect to the mapping $S$.

(iv) There exist $f_{\alpha_{1}}, f_{\alpha_{2}} \in A$ such that $d\left(T\left(f_{\alpha_{1}}\right), T\left(f_{\alpha_{2}}\right)\right)>$ $0.5 d\left(f_{\alpha_{1}}, S T f_{\alpha_{2}}\right)+d\left(f_{\alpha_{2}}, S T f_{\alpha_{1}}\right)$. That is, the mapping $T$ is not a non-self-Chatterjea-type mapping with respect to the mapping $S$.

Solution 2. By Example 13, it can be verified analogously that (i) and (ii) hold. For the proof of (iii) and (iv), we consider

$$
\begin{aligned}
& d\left(f_{\alpha_{1}}, S T f_{\alpha_{1}}\right)+d\left(f_{\alpha_{2}}, S T f_{\alpha_{2}}\right)=\left\|f_{\alpha_{1}}-S T f_{\alpha_{1}}\right\| \\
& +\left\|f_{\alpha_{2}}-S T f_{\alpha_{2}}\right\|=\| 1-\alpha_{1} \sin (\cdot) \\
& -S T\left(1-\alpha_{1} \sin (\cdot)\right)\|+\| 1-\alpha_{2} \sin (\cdot) \\
& -S T\left(1-\alpha_{2} \sin (\cdot)\right)\|=\| 1-\alpha_{1} \sin (\cdot) \\
& -S\left(0.3 \sqrt{\alpha_{1}} \sin (\cdot)-1\right)\|+\| 1-\alpha_{2} \sin (\cdot) \\
& -S\left(0.3 \sqrt{\alpha_{2}} \sin (\cdot)-1\right)\|=\| 1-\alpha_{1} \sin (\cdot) \\
& -\left(1-\left(0.25+0.5\left(0.09 \alpha_{1}\right)\right) \sin (\cdot)\right)\|+\| 1 \\
& -\alpha_{2} \sin (\cdot)-\left(1-\left(0.25+0.5\left(0.09 \alpha_{2}\right)\right) \sin (\cdot)\right) \| \\
& =\left|0.25+0.045 \alpha_{1}-\alpha_{1}\right|\|\sin (\cdot)\|+\mid 0.25+0.045 \alpha_{2} \\
& -\alpha_{2}|\|\sin (\cdot)\|=| 0.25-0.955 \alpha_{1}|+| 0.25 \\
& -0.955 \alpha_{2} \mid \\
& d\left(f_{\alpha_{1}}, S T f_{\alpha_{2}}\right)+d\left(f_{\alpha_{2}}, S T f_{\alpha_{1}}\right)=\left\|f_{\alpha_{1}}-S T f_{\alpha_{2}}\right\| \\
& +\left\|f_{\alpha_{2}}-S T f_{\alpha_{1}}\right\|=\| 1-\alpha_{1} \sin (\cdot) \\
& -S T\left(1-\alpha_{2} \sin (\cdot)\right)\|+\| 1-\alpha_{2} \sin (\cdot) \\
& -S T\left(1-\alpha_{1} \sin (\cdot)\right)\|=\| 1-\alpha_{1} \sin (\cdot) \\
& -S\left(0.3 \sqrt{\alpha_{2}} \sin (\cdot)-1\right)\|+\| 1-\alpha_{2} \sin (\cdot) \\
& -S\left(0.3 \sqrt{\alpha_{1}} \sin (\cdot)-1\right)\|=\| 1-\alpha_{1} \sin (\cdot) \\
& -\left(1-\left(0.25+0.5\left(0.09 \alpha_{2}\right)\right) \sin (\cdot)\right)\|+\| 1 \\
& -\alpha_{2} \sin (\cdot)-\left(1-\left(0.25+0.5\left(0.09 \alpha_{1}\right)\right) \sin (\cdot)\right) \| \\
& =\left|0.25+0.045 \alpha_{2}-\alpha_{1}\right|\|\sin (\cdot)\|+\mid 0.25+0.045 \alpha_{1} \\
& -\alpha_{2}|\|\sin (\cdot)\|=| 0.25+0.045 \alpha_{2}-\alpha_{1}|+| 0.25 \\
& +0.045 \alpha_{1}-\alpha_{2} \mid \text {. }
\end{aligned}
$$

Let $\alpha_{1}=0$ and $\alpha_{2}=0.25$ in (59). Then, we obtain

$$
\begin{aligned}
0.5 & \left(d\left(f_{0}, S T f_{0}\right)+d\left(f_{0.25}, S T f_{0.25}\right)\right) \\
& =0.5(|0.25-0.955(0)|+|0.25-0.955(0.25)|) \\
& =0.130625,
\end{aligned}
$$

$$
\begin{aligned}
0.5 & \left(d\left(f_{0}, S T f_{0.25}\right)+d\left(f_{0.25}, S T f_{0}\right)\right) \\
& =0.5(|0.25+0.045(0.25)-0| \\
& +|0.25+0.045(0)-0.25|)=0.130625 .
\end{aligned}
$$

respectively. Comparing (53) and (60), we obtain

$$
\begin{aligned}
d( & \left.T\left(f_{0}\right), T\left(f_{0.25}\right)\right) \\
& >0.5\left(d\left(f_{0}, S T f_{0}\right)+d\left(f_{0.25}, S T f_{0.25}\right)\right) \\
> & k\left(d\left(f_{0}, S T f_{0}\right)+d\left(f_{0.25}, S T f_{0.25}\right)\right)
\end{aligned}
$$

for all $k \in[0,1 / 2)$. Therefore, $T$ is not a non-self-Kannan-type mapping with respect to the mapping $S$. Similarly, comparing (53) and (61), we obtain

$$
\begin{aligned}
d( & \left.T\left(f_{0}\right), T\left(f_{0.25}\right)\right) \\
& >0.5\left(d\left(f_{0}, S T f_{0.25}\right)+d\left(f_{0.25}, S T f_{0}\right)\right) \\
> & k\left(d\left(f_{0}, S T f_{0.25}\right)+d\left(f_{0.25}, S T f_{0}\right)\right)
\end{aligned}
$$

for all $k \in[0,1 / 2)$. Therefore, $T$ is not a non-self-Chatterjeatype mapping with respect to the mapping $S$.

Corollary 15 (see [33, Theorem 3.3]). Let $A$ and $B$ be nonempty closed subsets of a complete metric space. Let $T$ : $A \rightarrow B$ and $S: B \rightarrow A$ satisfy the following conditions for some nonnegative number $k<1 / 2$ :

$\left(\mathrm{i}_{K}\right) S$ is nonexpansive.

$\left(\mathrm{ii}_{K}\right) d(T u, T v) \leq k[d(u, S T u)+d(v, S T v)]$ for all $u, v \in A$. $\left(\mathrm{iii}_{K}\right)$ The pair $(S, T)$ forms a weak $K$-cyclic contraction.

Then, there exist elements $x \in A$ and $y \in B$ such that

$$
\begin{aligned}
& d(x, T x)=d(A, B) \\
& d(y, S y)=d(A, B) \\
& d(x, y)=d(A, B) .
\end{aligned}
$$

If $x_{0}$ is any fixed element in $A, x_{2 n+1}=T x_{2 n}$, and $x_{2 n}=$ $S x_{2 n-1}$, then the sequences $\left\{x_{2 n}\right\}$ and $\left\{x_{2 n+1}\right\}$ converge to some best proximity points of $T$ and $S$, respectively. Further, if $x^{*}$ is another best proximity point of $T$, then

$$
d\left(x, x^{*}\right) \leq 2(1+2 k) d(A, B) .
$$

Proof. Letting $L=1, k_{1}=k_{3}=0$, and $k_{2}=k$ in Theorem 12, then we have the desired result.

Corollary 16 (see [33, Theorem 3.6]). Let $A$ and $B$ be nonempty closed subsets of a complete metric space. Let $T$ : $A \rightarrow B$ and $S: B \rightarrow A$ satisfy the following conditions for some nonnegative number $k<1 / 2$ :

$\left(\mathrm{i}_{C}\right) S$ is nonexpansive.

$\left(\mathrm{ii}_{C}\right) d(T u, T v) \leq k[d(u, S T v)+d(v, S T u)]$ for all $u, v \in A$.

(iii $\left.{ }_{C}\right)$ The pair $(S, T)$ forms a weak $K$-cyclic contraction. 
Then, there exist elements $x \in A$ and $y \in B$ such that

$$
\begin{aligned}
& d(x, T x)=d(A, B) \\
& d(y, S y)=d(A, B) \\
& d(x, y)=d(A, B) .
\end{aligned}
$$

If $x_{0}$ is any fixed element in $A, x_{2 n+1}=T x_{2 n}$, and $x_{2 n}=$ $S x_{2 n-1}$, then the sequences $\left\{x_{2 n}\right\}$ and $\left\{x_{2 n+1}\right\}$ converge to some best proximity points of $T$ and $S$, respectively. Further, if $x^{*}$ is another best proximity point of $T$, then

$$
d\left(x, x^{*}\right) \leq \frac{2(1+2 k)}{1-2 k} d(A, B) .
$$

Proof. Letting $L=1, k_{1}=k_{2}=0$, and $k_{3}=k$ in Theorem 12, then we have the desired result.

Remark 17. From the discovery of Examples 13 and 14, they are something beyond some assumptions and conditions of Corollaries 15 and 16. For this reason, the situations appearing above are important in causing Theorem 12.

\section{Competing Interests}

The author declares that there are no competing interests regarding the publication of this paper.

\section{Acknowledgments}

The author would like to acknowledge Naresuan University for financial support.

\section{References}

[1] K. Fan, "Extensions of two fixed point theorems of F. E. Browder," Mathematische Zeitschrift, vol. 112, pp. 234-240, 1969.

[2] J. B. Prolla, "Fixed-point theorems for set-valued mappings and existence of best approximants," Numerical Functional Analysis and Optimization, vol. 5, no. 4, pp. 449-455, 1983.

[3] S. Reich, "Approximate selections, best approximations, fixed points, and invariant sets," Journal of Mathematical Analysis and Applications, vol. 62, no. 1, pp. 104-113, 1978.

[4] V. M. Sehgal and S. P. Singh, "A generalization to multifunctions of Fan's best approximation theorem," Proceedings of the American Mathematical Society, vol. 102, no. 3, pp. 534-537, 1988.

[5] V. M. Sehgal and S. P. Singh, "A theorem on best approximations," Numerical Functional Analysis and Optimization, vol. 10, no. 1-2, pp. 181-184, 1989.

[6] V. Vetrivel, P. Veeramani, and P. Bhattacharyya, "Some extensions of Fan's best approximation theorem," Numerical Functional Analysis and Optimization, vol. 13, no. 3-4, pp. 397-402, 1992.

[7] M. A. Al-Thagafi and N. Shahzad, "Convergence and existence results for best proximity points," Nonlinear Analysis: Theory, Methods \& Applications, vol. 70, no. 10, pp. 3665-3671, 2009.

[8] C. Di Bari, T. Suzuki, and C. Vetro, "Best proximity points for cyclic Meir-Keeler contractions," Nonlinear Analysis: Theory, Methods \& Applications, vol. 69, no. 11, pp. 3790-3794, 2008.

[9] A. A. Eldred and P. Veeramani, "Existence and convergence of best proximity points," Journal of Mathematical Analysis and Applications, vol. 323, no. 2, pp. 1001-1006, 2006.
[10] A. P. Farajzadeh, S. Plubtieng, and K. Ungchittrakool, "On best proximity point theorems without ordering," Abstract and Applied Analysis, vol. 2014, Article ID 130439, 5 pages, 2014.

[11] S. Karpagam and S. Agrawal, "Best proximity point theorems for p-cyclic Meir-Keeler contractions," Fixed Point Theory and Applications, vol. 2009, Article ID 197308, 9 pages, 2009.

[12] B. Piatek, "On cyclic Meir-Keeler contractions in metric spaces," Nonlinear Analysis: Theory, Methods \& Applications, vol. 74, no. 1, pp. 35-40, 2011.

[13] S. Sadiq Basha, "Best proximity point theorems," Journal of Approximation Theory, vol. 163, no. 11, pp. 1772-1781, 2011.

[14] S. Sadiq Basha, "Best proximity point theorems generalizing the contraction principle," Nonlinear Analysis: Theory, Methods \& Applications, vol. 74, no. 17, pp. 5844-5850, 2011.

[15] S. Sadiq Basha, "Best proximity points: global optimal approximate solutions," Journal of Global Optimization, vol. 49, no. 1, pp. 15-21, 2011.

[16] S. Sadiq Basha, "Global optimal approximate solutions," Optimization Letters, vol. 5, no. 4, pp. 639-645, 2011.

[17] C. Vetro, "Best proximity points: convergence and existence theorems for $p$-cyclic mappings," Nonlinear Analysis: Theory, Methods \& Applications, vol. 73, no. 7, pp. 2283-2291, 2010.

[18] M. A. Al-Thagafi and N. Shahzad, "Best proximity sets and equilibrium pairs for a finite family of multimaps," Fixed Point Theory and Applications, vol. 2008, Article ID 457069, 2008.

[19] M. A. Al-Thagafi and N. Shahzad, "Best proximity pairs and equilibrium pairs for Kakutani mul-timaps," Nonlinear Analysis: Theory, Methods \& Applications, vol. 70, no. 3, pp. 1209-1216, 2009.

[20] W. K. Kim, S. Kum, and K. H. Lee, "On general best proximity pairs and equilibrium pairs in free abstract economies," Nonlinear Analysis: Theory, Methods \& Applications, vol. 68, no. 8, pp. 2216-2227, 2008.

[21] W. A. Kirk, S. Reich, and P. Veeramani, "Proximinal retracts and best proximity pair theorems," Numerical Functional Analysis and Optimization, vol. 24, no. 7-8, pp. 851-862, 2003.

[22] S. Sadiq Basha and P. Veeramani, "Best approximations and best proximity pairs," Acta Scientiarum Mathematicarum (Szeged), vol. 63, no. 1-2, pp. 289-300, 1997.

[23] S. Sadiq Basha and P. Veeramani, "Best proximity pair theorems for multifunctions with open fibres," Journal of Approximation Theory, vol. 103, no. 1, pp. 119-129, 2000.

[24] S. Sadiq Basha, P. Veeramani, and D. V. Pai, "Best proximity pair theorems," Indian Journal of Pure and Applied Mathematics, vol. 32, no. 8, pp. 1237-1246, 2001.

[25] P. S. Srinivasan, "Best proximity pair theorems," Acta Scientiarum Mathematicarum, vol. 67, no. 1-2, pp. 421-429, 2001.

[26] K. Włodarczyk, R. Plebaniak, and A. Banach, "Best proximity points for cyclic and noncyclic set-valued relatively quasiasymptotic contractions in uniform spaces," Nonlinear Analysis: Theory, Methods \& Applications, vol. 70, no. 9, pp. 3332-3341, 2009.

[27] K. Wlodarczyk, R. Plebaniak, and A. Banach, "Erratum to: 'Best proximity points for cyclic and noncyclic set-valued relatively quasi-asymptotic contractions in uniform spaces' [Nonlinear Anal. 70 (2009) 3332-3341. doi:10.1016/j.na.2008.04.037]," Nonlinear Analysis, vol. 71, pp. 3583-3586, 2009.

[28] K. Włodarczyk, R. Plebaniak, and C. Obczyński, “Convergence theorems, best approximation and best proximity for set-valued dynamic systems of relatively quasi-asymptotic contractions in cone uniform spaces," Nonlinear Analysis: Theory, Methods \& Applications, vol. 72, no. 2, pp. 794-805, 2010. 
[29] S. Sadiq Basha, "Common best proximity points: global minimization of multi-objective functions," Journal of Global Optimization, vol. 54, no. 2, pp. 367-373, 2012.

[30] S. Sadiq Basha, "Common best proximity points: global minimal solutions," TOP, vol. 21, no. 1, pp. 182-188, 2013.

[31] S. Sadiq Basha, N. Shahzad, and R. Jeyaraj, "Common best proximity points: global optimization of multi-objective functions," Applied Mathematics Letters, vol. 24, no. 6, pp. 883-886, 2011.

[32] N. Shahzad, S. Sadiq Basha, and R. Jeyaraj, "Common best proximity points: global optimal solutions," Journal of Optimization Theory and Applications, vol. 148, no. 1, pp. 69-78, 2011.

[33] S. Sadiq Basha, N. Shahzad, and R. Jeyaraj, "Best proximity points: approximation and optimization," Optimization Letters, vol. 7, no. 1, pp. 145-155, 2013.

[34] R. Kannan, "Some results on fixed points," Bulletin of the Calcutta Mathematical Society, vol. 60, pp. 71-76, 1968.

[35] S. K. Chatterjea, "Fixed point theorems," Comptes Rendus de l’Academie Bulgare des Sciences, vol. 25, pp. 727-730, 1972. 


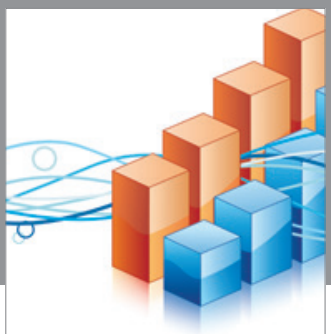

Advances in

Operations Research

vatem alat4

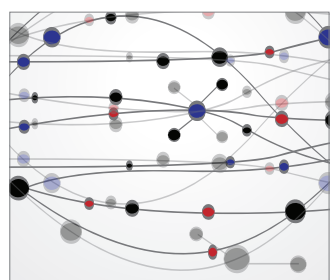

\section{The Scientific} World Journal
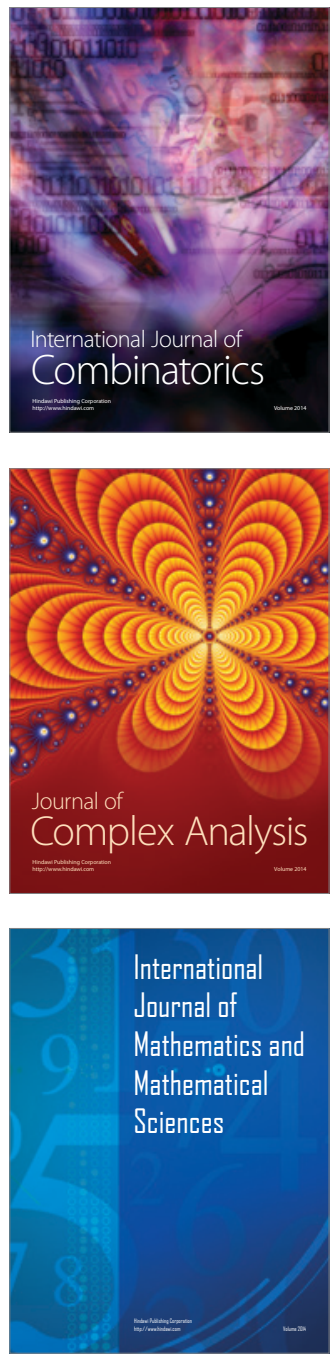
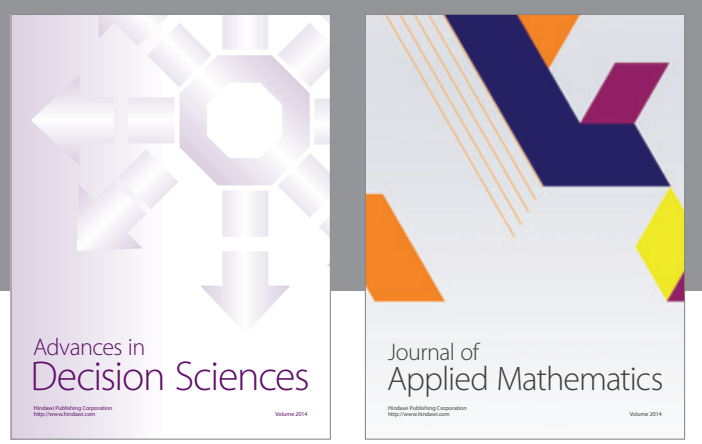

Algebra

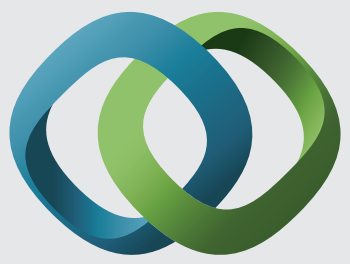

\section{Hindawi}

Submit your manuscripts at

http://www.hindawi.com
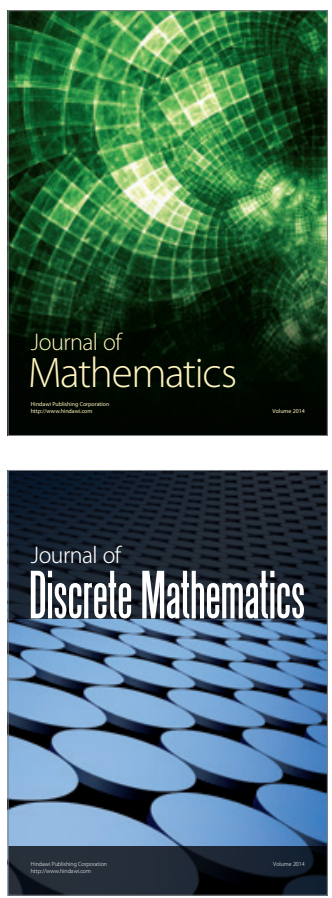

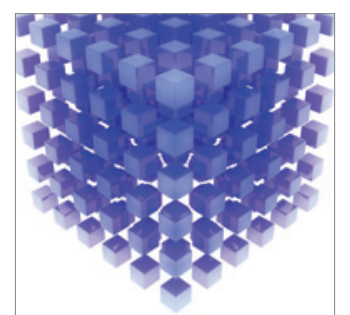

Mathematical Problems in Engineering
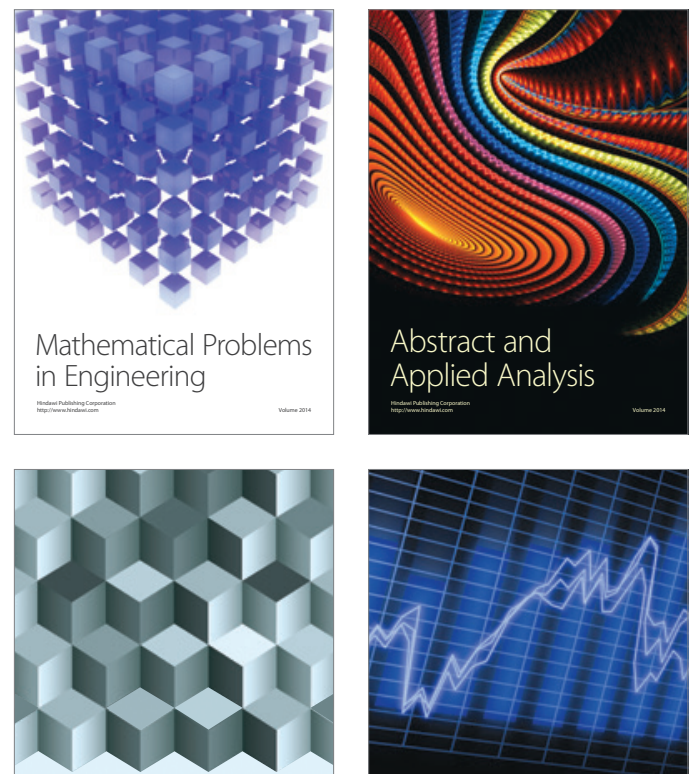

Journal of

Function Spaces

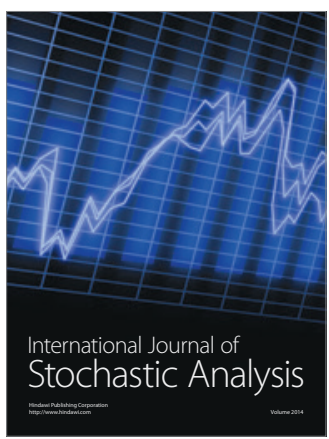

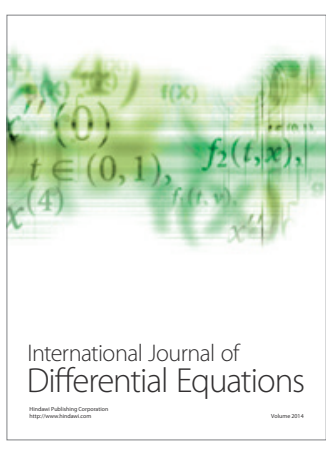
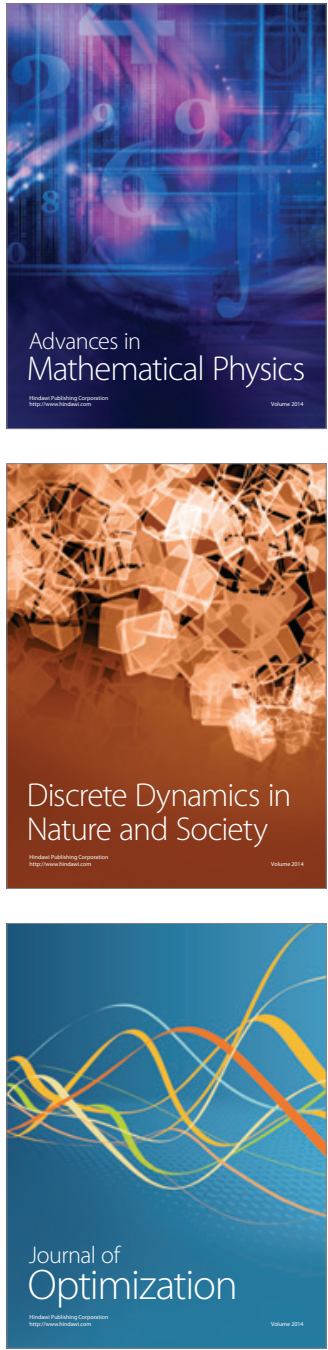